\title{
Technology and labour market in the European Union
}

\section{Andreea Burciu}

Bucharest University of Economic Studies, 6 Piata Romana, 1st district, Bucharest, 010374 Romania

PhD Candidate, Department of Cybernetics and Statistics

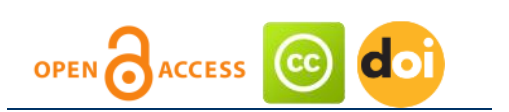

Article history:

Received: March 2, 2017

1st Revision: April 24,

2017

Accepted: April 30, 2017

\section{JEL classification: \\ $\mathrm{H} 75$ \\ M14}

DOI:

10.14254/jems.2017.2-1.3

\begin{abstract}
Nowadays, the digital economy represents the main engine of innovation, competitiveness and growth potential at European level, being a real opportunity for entrepreneurs and Small and Medium Enterprises (SMEs). The faster a company embraces technology, the more successful it can become. Technology dominates the present times more and more, preparing new and challenging horizons, leading the world to a new dimension, improving our lives in all the possible ways. Technology holds a real challenge for the labour market which, on the one hand, should adapt to the new pace imposed by computers and smart devices. On the other hand, there is an increasing and stringent demand of highly qualified personnel to get further the current "tech revolution". In this context, it is interesting to study how the EU Member States have developed their infrastructure, education and which is the status of labour market in IT\&C, using a cluster analysis applied on 2014 data obtained from Eurostat.
\end{abstract}

Keywords: cluster analysis, labour market, technology, innovation.

\section{Introduction}

The digital economy is a state of the economy that uses information generated by citizens' and organizations' activities and transactions, saved in data warehouses (Ivan, 2003). On the other hand, (Oprescu \& Eleodor, 2014) show that the digital economy is composed by digital technology markets that facilitate the goods and services exchange by electronic means. (Duhăneanu \& Marin, 2014) show that the digital economy had impact on all economy sectors and social activities: trade, transport, financial services, production, education, healthcare, and media, among others.

The digital economy is an economy driven by speed, productivity, transparency and led by electronic coins. Thanks to the digital economy the concept of competition between companies has changed and now...the companies fight the time rather than each other: the faster they reach their clients, the more successful they can become. Of course, most of the companies and entities have invested very much in developing the internal and external processes, many of them evolving to efficiency by cutting costs, counting on workforce mobility, cloud computing, ERP systems and social media. 
We are currently witnessing the development of a new ecosystem that designs effective ways of working, to speed, adjustment to new consumer approaches, real exchange of information, and high production rates by using IT\&C. In this landscape, the labour market represents a key element, which has to cope with these changes, embrace them and finally use them. The human capital faces now the artificial intelligence, the endless processing power of the computers, the Internet knowledge. The human resources must develop the abilities of managing big data, improving computers' performance, creating new means of communication, growing the digital ecosystem. At the same time, we should acknowledge the fact that from the organisational perspective, the hierarchy as we know it will be replaced by the horizontal relationship between people, based on trust, cooperation and collaboration, where employees are rather partners in the business. This approach has better chances of engaging employees in delivering a quality work, bringing their contribution to the development and success of the organisation they work for. Creativity, innovation, continuous training are ways to contribute to the competitive advantage of the entity, fact that will eventually lead to a change of generations in the management level, with people that understand and apply the new ways of leading without building titles, barriers and breaks but building bridges. As technology has opened the global market for anyone, regardless of the location, distribution channels and dimensions, the faster a company uses IT\&C, the more it can compete with the others. According to (OECD, 2011), IT\&C represents the production of goods and services of an industry that processes information and communications through electronic means, including the transmitting and displaying them. On the other hand, (Eurostat, 2015) defines IT\&C as the global economic sector that covers all the technical ways to manage information and support communication (hardware and software computers), which has the role of improving effectiveness and the efficiency of the companies, increasing competitiveness, encouraging innovation. All over the world, companies are adjusting their business models through anticipating consumers' options and preferences, while electronic devices are part of the everyday life of millions of people and the data generated is huge. Digitalisation has evolved from computers' creation, to Internet's launch and now to a new era defined by new and disruptive technologies as 3D printing, sensors, drones, high-tech houses remotely controlled wearables. As technology becomes more and more widespread, it changes the way we interact, socialise, communicate and work together, it is important to study what the IT\&C brings into economy and how it influences the labour market at EU level, since the demand for qualified workforce in this area is higher and higher every year.

The European Union's institutions have identified seven initiatives that should drive the authorities' efforts for reaching a high level of competitiveness and leading Europe to a new decade. One of the initiatives refers to the Digital Agenda for Europe which aims to develop the digital single market in order to generate smart, sustainable and inclusive growth in Europe. The Agenda has 7 pillars, as follows:

- Achieving the digital single market

- Enhancing interoperability and standards

- Strengthening online trust and security

- Promoting fast and ultra-fast Internet access for all

- Investing in research and innovation

- Promoting digital literacy, skills and inclusion

- IT\&C-enabled benefits for EU society.

The digital agenda highlights the fact that IT\&C generates an increase in the demand for workforce. The paradox is that even though Europe faces quite a high unemployment rate, the available vacancies in the technology sector are close to 900000 . The digital agenda aims to consolidate EU's position in terms of productivity seeking to minimise the gap to the United States, Japan, China and India. The EU proposes an upgrade in e-skills, by creating the policy paper named "Grand Coalition for Digital Jobs and Skills", which represents a partnership between government, universities, enterprises in order to manage the IT\&C education. There are also national coalitions in countries like Bulgaria, Greece, Malta, Latvia, Lithuania, Romania and Poland (European Commission, 2014). "Grand Coalition for Digital Jobs and Skills" focuses on concrete actions, that are able to be implemented on short time with local impact, at every Member State's level, being built based on best practices adjusted to the national data.

The trends show that the IT\&C workplaces have risen yearly with a $4 \%$ rate and the management jobs in the field with an $8 \%$ rate. The labour market in the EU comprises over 8 million employees which represent only 3.7\% of the workforce. (European Commission, 2014).

\section{METHODOLOGY}

For a proper development of the IT\&C labour market it is necessary to have the best framework able to ensure the progress of the human capital and the quality growth of market's 
outputs. Using data from Eurostat for the EU-28 Member States, the purpose of this paper is to analyse the way the EU - 28 Member States cluster based on several common characteristics defined by three main types of indicators:

- existent infrastructure at every country's level - it is the way to create the framework for a functional and sustainable IT\&C labour market. The variable taken into consideration is households' access to Internet (as a measure of technology's accessibility);

- education and knowledge development in tech area - without this mean, it is impossible to grow a viable, competitive and innovative workforce. The variables taken into consideration measure the percentage of students engaged in studying science, mathematics and computers, graduates in science, mathematics and technology, companies that offered training in IT\&C and the e-skills level.

- the labour market in tech field - the specific variables that study and reflect the demands on the market: unemployment rate, the share of population engaged in IT\&C, number of specialists in IT\&C and the average wage (euro/year), the number of companies that hired IT\&C specialists as a proxy variable for the demand in this field.

First of all, we should standardize data in order to ensure comparability. There are several ways of doing this step, but for this paper I will choose the $\mathrm{z}$ scores which assumes that the data is transformed as each variable has mean $=0$ and the standard deviation $=1$. Using this method requires isolating the outliers that can influence the database.

Cluster analysis is a multivariate technique that aims to classify objects based on their similarity, while the distance between clusters is as large as possible. The main steps for this method are:

- defining a similarity (proximity) measure between entities based on the observed variables;

- setting up rules to differentiate the classes.

There are two methods for grouping the cases: hierarchical methods (they start from the number of cases and through multiple iterations they reach a single class) or non-hierarchical methods (they start from a pre-defined number of random values that will eventually build the clusters). 2005):

The statistical theory shows there are three main types of hierarchical analysis (Spircu,

a) Hierarchical Cluster Analysis - a method that says that every data group is included in a larger group; it is not recommended for too large databases;

b) Disjoint Cluster Analysis - it is an iterative method that groups all individuals in a single class and afterwards redistributes them based on the similarity with other individuals;

c) K-mean clustering - utilising the mean of the individuals, it aims to minimise the individuals' variance in every class and to maximise the variance between classes.

The distance between clusters can be measured as follows (Rotariu, Badescu, Culic, \& Mezei, 1999):

a) SEUCLID - square of Euclidian distance:

b) EUCLID - Euclidian distance:

$$
d(X, Y)=\Sigma i(X i-Y i)^{2}
$$

$$
d(X, Y)=\sqrt{ }(\Sigma i(X i-Y i) 2)
$$

c) BLOC (Manhattan) - standard deviation sum:

d) CEBYCHEV - maximum standard deviation:

$$
d(X, Y)=\Sigma i(X i-Y i)
$$

e) MINKOWSKI - generalised Euclidian distance:

$$
d(X, Y)=\operatorname{maxi}(X i-Y i)
$$

f) POWER (p, r) - MINKOWSKI generalised:

$$
d(X, Y)=\left(\Sigma i(X i-Y i)^{p}\right) 1 / p
$$

$$
d(X, Y)=\left(\Sigma i(X i-Y i)^{p}\right) 1 / r
$$
2005):

In order to evaluate the classes' proximity, we can use one of the methods below (Spircu,

a) Single linkage - also named nearest neighbour, it measures the distance between the closest elements, belonging to different classes. The downside is that it can create heterogeneous groups because it doesn't take into account the outliers;

b) Complete linkage - also known as farthest neighbour - it is the reverse of the one above, meaning that it measures the distance between furthest elements;

c) Average linkage - weighted - uses the average distance between all pairs of objects in any two cluster.

(Rotariu, Badescu, Culic, \& Mezei, 1999) add four more methods: 
d) Single linkage between groups takes into consideration the average distance between the elements of two groups;

e) Average linkage within groups - it is calculated the mean of reunited classes of each pair of clusters and it is chosen the pair which has the lowest mean;

f) Ward method - uses the incremental sum of squares; that is, the increase in the total within-cluster sum of squares as a result of joining two clusters; clusters

g) Centroid clustering - uses the Euclidean distance between the centroids of the two

For this analysis I have used SPSS software. Step one is standardising the data. At the second step, I will select Analyze> Classify > Hierarchical cluster. For our analysis I used Complete linkage method (farthest neighbour) using square of Euclidian distance between clusters.

\section{RESULTS AND DISCUSSION}

The agglomeration schedule obtained after computing the data is shown below.

\begin{tabular}{|c|c|c|c|c|c|c|}
\hline \multirow[t]{2}{*}{ Stage } & \multicolumn{2}{|c|}{ Cluster Combined } & \multirow[t]{2}{*}{ Coefficients } & \multicolumn{2}{|c|}{$\begin{array}{c}\text { Stage Cluster First } \\
\text { Appears }\end{array}$} & \multirow[t]{2}{*}{ Next Stage } \\
\hline & Cluster 1 & Cluster 2 & & Cluster 1 & Cluster 2 & \\
\hline 1 & 15 & 16 & 2,969 & 0 & 0 & 8 \\
\hline 2 & 6 & 24 & 4,442 & 0 & 0 & 13 \\
\hline 3 & 21 & 23 & 4,575 & 0 & 0 & 16 \\
\hline 4 & 8 & 25 & 4,997 & 0 & 0 & 7 \\
\hline 5 & 11 & 19 & 5,325 & 0 & 0 & 17 \\
\hline 6 & 1 & 7 & 5,364 & 0 & 0 & 14 \\
\hline 7 & 4 & 8 & 5,815 & 0 & 4 & 9 \\
\hline 8 & 3 & 15 & 5,869 & 0 & 1 & 16 \\
\hline 9 & 4 & 10 & 6,755 & 7 & 0 & 19 \\
\hline 10 & 22 & 26 & 7,973 & 0 & 0 & 18 \\
\hline 11 & 9 & 27 & 9,446 & 0 & 0 & 14 \\
\hline 12 & 13 & 17 & 9,995 & 0 & 0 & 19 \\
\hline 13 & 6 & 28 & 10,993 & 2 & 0 & 21 \\
\hline 14 & 1 & 9 & 11,378 & 6 & 11 & 22 \\
\hline 15 & 2 & 20 & 12,113 & 0 & 0 & 22 \\
\hline 16 & 3 & 21 & 12,213 & 8 & 3 & 20 \\
\hline 17 & 11 & 18 & 16,653 & 5 & 0 & 23 \\
\hline 18 & 12 & 22 & 16,755 & 0 & 10 & 24 \\
\hline 19 & 4 & 13 & 16,933 & 9 & 12 & 23 \\
\hline 20 & 3 & 14 & 19,150 & 16 & 0 & 21 \\
\hline 21 & 3 & 6 & 20,973 & 20 & 13 & 24 \\
\hline 22 & 1 & 2 & 22,333 & 14 & 15 & 25 \\
\hline 23 & 4 & 11 & 24,363 & 19 & 17 & 25 \\
\hline 24 & 3 & 12 & 35,528 & 21 & 18 & 26 \\
\hline 25 & 1 & 4 & 40,076 & 22 & 23 & 26 \\
\hline 26 & 1 & 3 & 66,998 & 25 & 24 & 0 \\
\hline
\end{tabular}

\section{Source: own calculations}

The first iteration shows that the shortest distance between state number 15 (Latvia) and state number 16 (Lithuania) was 2.969. Obviously, Latvia and Lithuania will form a first group.

Then Croatia (state 6) will join Slovakia (state 24) forming a new group, as they don't appear in a former cluster (stage cluster first appears). Next stage column show which is the step where we can find again this newly formed group (step 13). The algorithm has 26 stages (n-1 number of countries taken into consideration). We must mention that one EU Member State (Cyprus) is eliminated from the analysis since it misses a value.

The dendogram is the graphic of the clusters obtained, making the information more accessible. After computing the data in SPSS and visualising the dendogram and the results in the dissimilarity matrix, we can see that there are four independent clusters. 
Figure 1: Dendogram

Dendrogram using Complete Linkage

Rescaled Distance Cluster Combine

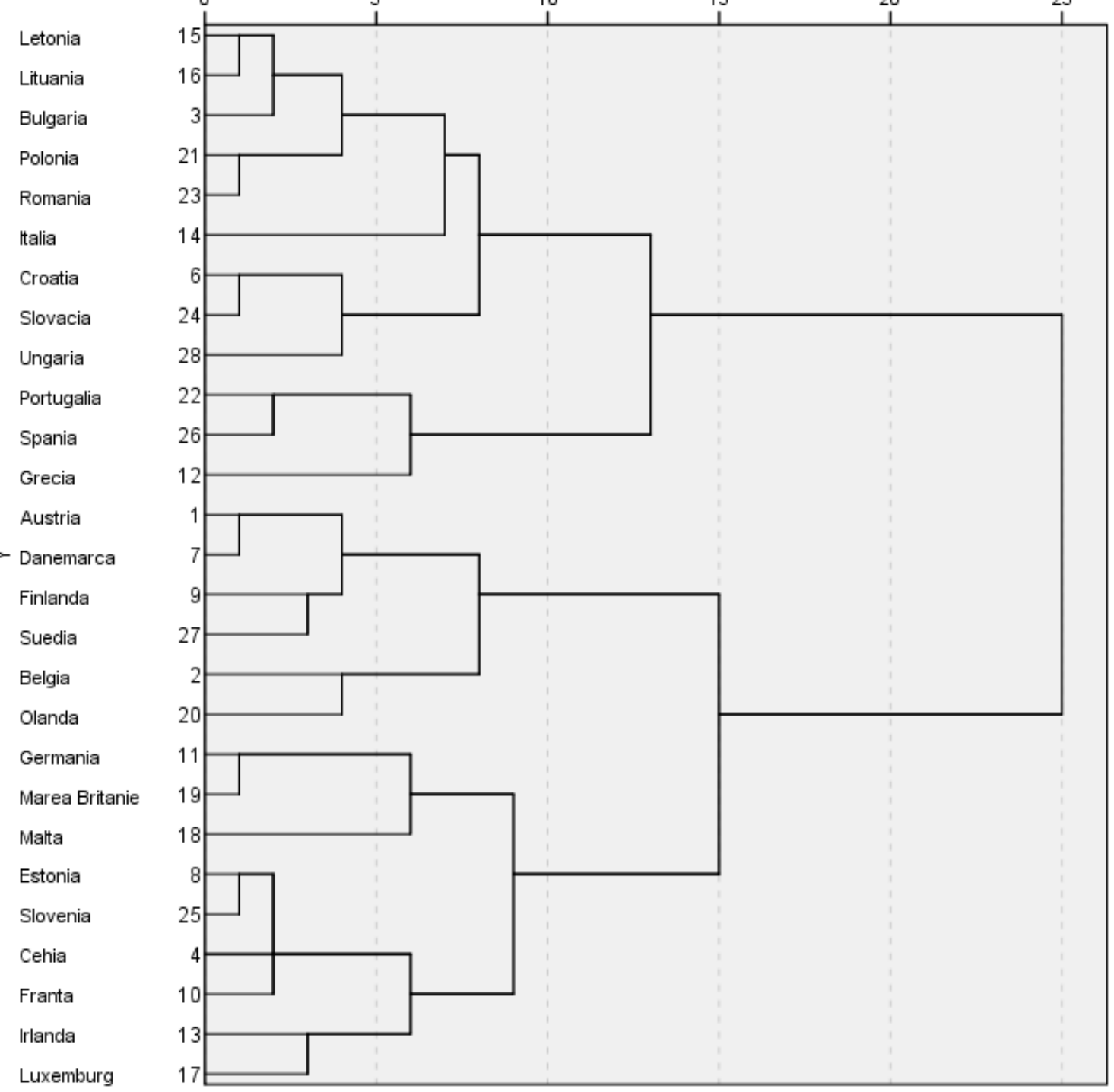

Source: own calculations

Table 2: EU Member States clusters

\begin{tabular}{|l|l|}
\hline \multicolumn{1}{|c|}{ Cluster } & \multicolumn{1}{c|}{ State } \\
\hline Cluster 1 & Bulgaria, Croatia, Italy, Latvia, Lithuania, Poland, Romania, Slovakia, Hungary \\
\hline Cluster 2 & Portugal, Spain, Greece \\
\hline Cluster 3 & Austria, Denmark, Finland, Sweden, Belgium, The Netherlands \\
\hline Cluster 4 & $\begin{array}{l}\text { Germany, United Kingdom, Malta, Estonia, Slovenia, Czech Republic, France, } \\
\text { Ireland, Luxembourg }\end{array}$ \\
\hline
\end{tabular}

\section{Source: own calculations}

According to the results for the 12 variables in 2014, in the first cluster we have the group of the lowest performers, the Eastern European countries that joined the EU after 2014, except Italy. Emerging markets, with potential, they are mainly targeted by the outsourcing industries that relocate for lesser costs. Characterised by a low access to Internet, but a good speed, a low percentage of graduates of science, mathematics and IT\&C, low training in IT\&C, an average unemployment rate, low wages, and not so many persons employed in IT\&C, these countries can be classified as the catching up cluster. They have the prerequisites to reach the other countries, yet they need investments and a better educational system to cover the needs of the labour market in this domain. The good news is that these countries have had a very good progress in the last few years in all indicators. 
In the second cluster we meet three countries seriously affected by the latest financial crisis. Their presence in this cluster is justified by their characteristics, very similar to each other, but very different from the other clusters. We can name this cluster the crisis cluster.

The third cluster includes the super performing in education countries. They rule in terms of access to Internet, training of the workforce and have the largest number of IT\&C specialists, adding up that they don't have a high unemployment. These countries are the ones that create the added value at EU's level, the innovative engine of the IT\&C sector, the education cluster.

The last cluster contains the Europe's Silicon Valley (UK), being the main tech market if we take into consideration the start-ups number in this sector, Germany which is a close follower of the UK (Berlin is an important hub at EU level). These countries don't have the same educational system as the countries in the third cluster, yet they have a very developed labour market in this area, hosting many start-ups and having incubators and venture capitalists that invest a lot in developing the entrepreneurial ecosystem. Estonia is another notable presence in this cluster, being the first country to introduce the e-residency - a transnational digital identity available to anyone in the world interested in administering a location-independent business online. E-Residency additionally enables secure and convenient digital services that facilitate credibility and trust online (https://e-estonia.com/e-residents/about). Ireland is the home of many IT companies from across the Ocean as it offers a proper taxation system and other facilities for them. Malta may seem a surprise for this group, but if we have a closer look at its indicators, it is a leader/is in top of the EU Member States that have a high speed Internet, a large number of science, maths and computer graduates, a high percentage of persons employed in IT\&C and a low unemployment rate. We can surely call this cluster the leaders' cluster.

\section{CONCLUSIONS}

The EU Member States split in four clusters, based on the three dimensions analysed with several indicators. The way they combine is a sign of their stage of development, but also it has to do with the people's eagerness to embrace technology and to include it in their everyday work. As we noticed, we don't have an Eastern and Western Europe dimension, but the clusters are mixed. This study can be used as a beginning point for deepening the discussions regarding the labour market in the EU facing the new challenges ahead. It could be useful an analysis in each country and the specific solution in order to shift the skills and knowledge from traditional sectors to technology, helping people adapt and face this new era that has already begun.

\section{Appendix A. Supplementary material}

Supplementary data associated with this article can be found, in the online version, at http://dx.doi.org/10.14254/jems.2017.2-1.3

\section{Funding}

The authors received no direct funding for this research.

\section{Citation information}

Burciu, A. (2017). Technology and labour market in the European Union. Economics, Management and Sustainability, 2(1), 36-42. doi:10.14254/jems.2017.2-1.3.

\section{References}

Duhăneanu, M., \& Marin, F. (2014). Agenda digitală pentru Europa: riscuri și oportunități într-o economie digitală. International Conference of the Institute for Business Administration in Bucharest, 15, pp. 67-77. Bucharest. Retrieved from http://www.srac.ro/calitatea/arhiva/supliment/2014/C-as_Vol.15_S4_Sept-2014.pdf

European Commission. (2014.a.). Digital Agenda for Europe. Luxemburg. Retrieved from http://europa.eu/pol/pdf/flipbook/ro/digital_agenda_ro.pdf

European Commission. (2014.b.). Digital Agenda for Europe. Retrieved from https://ec.europa.eu/digital-agenda/en/grand-coalition-digital-jobs

Eurostat. (2015). Glossary:Information and communication technology (ICT). Retrieved from http://ec.europa.eu/eurostat/statisticsexplained/index.php/Glossary:Information_and_communication_technology_(ICT) 
Ivan, I. (2003). Economia digitală. Retrieved martie 21, 2015. Retrieved from www.ionivan.ro/economie-digitala.rtf

OECD. (2011). Guide to Measuring the Information Society. OECD Publishing.

Oprescu, G., \& Eleodor, D. (2014). Impactul dezvoltării economiei digitale asupra concurenței. International Conference of the Institute for Business Administration in Bucharest, 15, pp. 2132. Bucharest. Retrieved from http://www.srac.ro/calitatea/arhiva/supliment/2014/Cas_Vol.15_S4_Sept-2014.pdf

Rotariu, T., Badescu, G., Culic, I., \& Mezei, E. (1999). Metode statistice aplicate in stiintele sociale. Iasi: Polirom Publishing house.

Spircu, L. (2005). Analiza datelor. Aplicații economice. Bucharest: ASE Publishing house.

Republic of Estonia. (2017). Join the new digital nation. Retrieved from https://e-estonia.com/eresidents/about

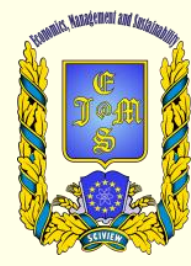

(c) 2016-2017, Economics, Management and Sustainability. All rights reserved.

This open access article is distributed under a Creative Commons Attribution (CC-BY) 4.0 license.

You are free to:

purpose, even commercially.

The licensor cannot revoke these freedoms as long as you follow the license terms.

Under the following terms:

Attribution - You must give appropriate credit, provide a link to the license, and indicate if changes were made.

You may do so in any reasonable manner, but not in any way that suggests the licensor endorses you or your use.

No additional restrictions

You may not apply legal terms or technological measures that legally restrict others from doing anything the license permits.

Economics, Management and Sustainability (ISSN: 2520-6303) is published by Scientific Publishing House "CSR", Poland, EU and Scientific Publishing House "SciView", Poland

Publishing with JEMS ensures:

- Immediate, universal access to your article on publication

- High visibility and discoverability via the JEMS website

- Rapid publication

- Rapid publication

- Discounts and waivers for authors in developing regions

Submit your manuscript to a JEMS at http://jems.sciview.net or submit.jems@sciview.net 